\title{
Productos cárnicos a base de carne de equino
}

\section{Meat products based on horse meat}

\author{
María Alejandra Ballesteros Mejía* \\ Universitaria Agustiniana-UNIAGUSTINIANA \\ Bogotá, Colombia \\ Jessica Torres Giraldo** \\ Universitaria Agustiniana-UNIAGUSTINIANA \\ Bogotá, Colombia
}

*maria.ballesterosm@uniagustiniana.edu.co

**jessica.torresg@uniagustiniana.edu.co

Articulo de investigación

Recepción: 01 de agosto de 2019. Aceptación: 30 de agosto de 2019

Cómo citar este artículo

Ballesteros, M., y Torres, J. (2019). Productos cárnicos a base de equino. Sosquua 1(1), 33-56. Recuperado a partir de http:// cipres.sanmateo.edu.co/index.php/sosquua 


\section{Resumen}

El objetivo principal de la presente investigación fue elaborar productos alimenticios a base de carne de equino. La materia prima se obtuvo de la planta de sacrificio "Los Cristales", ubicada en el municipio de Mosquera, Cundinamarca, avalada por el INVIMA como planta de beneficio con clasificación II y normativa legal vigente. Posteriormente se elaboró cabano y jerky para aplicarlos en preparaciones de cocina caliente como empanadas, marranitas, tacos, tapas españolas, pastas, ensaladas, arroz español (arroz meloso), arroz atollado, frijolada y pechuga de pollo. Finalmente se realizaron encuestas acerca de la aceptación de los productos base (cabano y jerky), encontrando que es un producto consumido con frecuencia, obteniendo un alto nivel de aceptación. Igualmente al realizar encuestas descriptivas sobre las preparaciones gastronómicas,fueron aceptadas, prefiriendo las empanadas (cabano) y los nachos (jerky).

Palabras clave: carne; equino; planta de beneficio; cabano; jerky; productos alimenticios.

\section{Abstract}

The main objective of this research was to produce food products based on equine meat. The raw material was obtained from the slaughter plant "Los Cristales", located in Mosquera's town, in Cundinamarca, endorsed by INVIMA as a profit plant with classification II and legal regulations in force. The Cabano and Jerky were prepared, and then applied, in hot cuisine preparations as empanadas, marranitas, tacos, tapas españolas, pastas, salads, arroz meloso, arroz atollado, frijolada and galantina de pollo. Finally, surveys demonstrated the acceptance of the base products (Cabano and Jerky) finding that it is a commonly consumed product obtaining a high level of acceptance. Also, in the conducting descriptive surveys, the gastronomic preparations were accepted and having preferences for the empanadas (Cabano) and nachos (Jerky).

Keywords: meat; equine; profit plant; cabano; Jerky; food products. 


\section{Introducción}

La presente investigación tiene por objetivo reemplazar la carne de res y cerdo principalmente por carne de equino en los productos cárnicos cabano y jerky, cumpliendo parámetros legales y sanitarios, así como especificaciones propias de este tipo de productos. Además, darle la posibilidad al consumidor de conocer la obtención de carne equina, en este caso del matadero Los Cristales ubicado en Mosquera - Cundinamarca, certificado por el INVIMA como planta de beneficio animal de equinos, clasificado clase III donde se cumple con requisitos generales señalados en decretos 2278 y 1594 de AÑO y el cual debe tener una capacidad instalada para sacrificar de 120 a 160 equinos en un turno de 8 horas (INVIMA, 2014).

La carne de equino tiene aportes nutricionales mayores comparados con la carne de res y cerdo, gracias a su contenido de proteína en un 22\%, grasa en 3\% y minerales. Debido a esto, la investigación se realiza para brindar una alternativa de consumo de proteína animal, presentando información completa y real de los nuevos usos que se le pueden dar a la carne equina, en este caso reflejada en productos cárnicos fermentados, además de generar nuevas perspectivas y conceptos sobre ella.

El proyecto partió de un tipo de investigación exploratoria, tema de investigación poco estudiado o hay investigaciones similares pero llevadas a otros contextos. Este tipo de investigación nos ayudó a identificar las problemáticas con respecto al rechazo de la carne de equino y con ello aumentar una familiaridad con el consumo.

Se desarrolló un diseño cuasi-experimental, el cual prueba la existencia de una relación causal entre dos o más variables. Se determinó una muestra dividida en estudiantes de sexto semes- 
tre de arquitectura (no entrenados), estudiantes de Tecnología en gastronomía de quinto semestre (semi entrenados), y profesionales en gastronomía (entrenados) de la Universitaria Agustiniana. Ellos fueron expuestos a las encuestas, las cuales se establecieron de una manera no aleatoria para fijar variables de carácter social y organoléptico como el sabor, la textura, el olor, el posible consumo diario y los usos en preparaciones gastronómica.

Basados en lo anterior, determinamos los porcentajes de aceptación de los productos realizados. Así mismo tuvimos una manera de verificar los datos expuestos que arrojaron una explicación real, vista desde una mirada objetiva y solo guiada por el análisis de los datos recogidos, los cuales nos ayudaron a contestar preguntas de investigación y, a través de ella, probamos las hipótesis alternativas del diseño cuasi-experimental.

\section{Materiales y técnicas}

\section{Materiales}

Carne

La carne es el tejido muscular de los animales que ha sufrido rigidez cadavérica. Esta debe provenir de animales sanos y tratados higiénicamente. 
Grasa

La grasa, destinada para la elaboración de productos cárnicos, proviene del tejido dorsal, de la pierna o papada y resistente al corte. La más utilizada es la grasa de cerdo por sus características de sabor y aroma, que le aportan al producto. Esta grasa debe mantenerse en refrigeración o congelación para impedir alteraciones.

Agua

El agua cumple la función de disolver sal y demás ingredientes. Además, disminuye los costos de elaboración de los productos.

La cantidad de sal utilizada en la elaboración de embutidos está entre el 1\% y 5\%. Su función principal es darle sabor al producto, actuar como conservante, solubilizar proteínas y aumentar la retención del agua de las proteínas. Igualmente, la sal retarda el crecimiento microbiano, sin embargo, puede contribuir al enranciamiento de las grasas.

\section{Azúcares}

Contribuyen al sabor y al aroma. Sirven de energía para las bacterias ácido lácticas, para la producción de ácido láctico, especialmente en productos fermentados. Los azúcares, generalmente, utilizados son la lactosa, la glucosa, el almidón, el jarabe de maíz, entre otros. 


\section{Nitratos y nitritos}

Actúan con la sal y el azúcar en el curado de la carne para desarrollar el color, modificar los sabores y prevenir el crecimiento de microorganismos. Desempeñan un papel importante en la aparición del color rosado, dan un sabor y un aroma al producto. Se usan en cantidades muy pequeñas y no deben exceder su cantidad recomendada (6 g de Nitrito por $100 \mathrm{~g}$ de sal curante: $0.2 \mathrm{~g}$ / kg de carne).

\section{Fosfatos}

Se utilizan para aumentar la retención de agua en los productos cárnicos y ayudar a solubilizar las proteínas. Lo recomendado es $3 g / k g$ de carne.

\section{Especias y condimentos}

Las especias y condimentos son sustancias de origen vegetal que cumplen la función de aportar sabores y olores a los productos. Generalmente se utiliza cebolla y ajo frescos (también en polvo), así como pimienta, pimentón, laurel, tomillo, jengibre, canela, clavos de olor, comino, perejil, tomillo, entre otros.

Según la Norma Técnica Colombiana 4423 (especias y condimentos) del Instituto Colombiano de Normas Técnicas (ICONTEC), el condimento es un producto constituido por una o más especias u oleorresinas de especias, mezcladas con otras sustancias alimenticias, listos para su uso inmediato. Los condimentos que se añaden tienen la función de darle a la carne un color intenso, así como prevenir la proliferación de microorganismos, dándole al producto un alto grado de protección contra la oxidación. 


\section{Tripas naturales y artificiales}

Son fundamentales debido a que contienen al resto de los ingredientes después de mezclarlos. Las tripas naturales corresponden a partes del tracto gastrointestinal de bovinos, porcinos, ovinos y caprinos. Las tripas artificiales son elaboradas a partir de celulosa y colágeno y pueden tener diferentes calibres.

\section{Técnicas utilizadas}

\section{Deshidratación}

Es un método de conservación que consiste en reducir, como mínimo, el 13\% del contenido de agua en el alimento. Es una técnica artificial donde el alimento es expuesto a una corriente de aire caliente, generando el mismo resultado en menor tiempo y de manera controlada. La deshidratación no solo es útil para alargar la vida de nuestros productos, sino también nos facilita el almacenaje, el transporte y la manipulación de los mismos.

\section{Carne deshidratada}

Es la aplicación de la técnica de la deshidratación en la carne con la finalidad de reducir el porcentaje de agua, para así evitar la proliferación de microorganismos patógenos e incrementar la cantidad de proteínas de la carne. 


\section{Salazón}

La salazón es un método de conservación utilizado en la antigüedad para evitar el crecimiento de microorganismos. Para realizarlo se utiliza una capa gruesa de sal (gruesa, marina o refinada), azúcar, nitritos y nitratos como ingredientes principales, sobre toda la superficie de la carne, con el fin de que se deshidrate y que el proceso de descomposición sea más lento.

\section{Maduración}

Después del ahumado, se procede a colocar el producto unos días al aire en lugares frescos, sombreados y bien ventilados para que la carne pierda más del $50 \%$ de su peso original. Aunque perder su peso es una merma, su contenido alimenticio se incrementa en igual proporción ya que las proteínas se concentran.

\section{Ahumado}

El ahumado es una de las técnicas de conservación de alimentos más antigua. Este método consiste en exponer los alimentos al humo de algunas maderas que son de olor agradable, y de efecto antibiótico, para aportar características organolépticas buenas y para preservarlos de la descomposición. 


\section{Productos cárnicos elaborados}

Jerky

El jerky (Charqui en América del Sur) proviene del quechua, nombre que designaban los Incas a las tajadas de carne, frutas o legumbres secadas al sol. Según Rodríguez (1994), los pueblos aymaras en Perú, ante la necesidad de conservar la carne de consumo de camélidos domésticos (llamas y alpacas), desarrollaron una técnica de deshidratación utilizando los rayos del sol y la sal. Ello dio origen al conocido Charqui, que hoy en día se sigue utilizado.

Países como Sudáfrica, Rusia, China, Turquía y Egipto, entre otros, son consumidores de la carne seca. Por esto, ha tomado diferentes nombres en cada lugar sin dejar a un lado la popularidad que ha alcanzado. Sin embargo, ha sido controversial encontrar snacks de jerky en países occidentales debido a que generalmente se consumen productos cárnicos húmedos como lo son los embutidos.

Desde hace miles de años la carne ha sido secada principalmente para ser conservada de manera sencilla y natural. Así, cada región del mundo obtuvo un método en particular para hacerlo, añadiendo especias y condimentos propios. Además, cada vez se perfeccionó el proceso de obtención de la carne, iniciando con la clasificación de las mejores partes del animal que se destacaban por tener menos grasa y más musculatura para darle textura perfecta al producto. Gracias a sus métodos de conservación, como la deshidratación y la salazón, en el jerky se incrementó el alto contenido de proteína que la carne de equino posee. También se inhibieron los posibles riesgos microbiológicos, haciendo del producto apto para el consumo y libre de posibles contaminaciones. 
En relación con la diferenciación de la carne seca con la carne fresca comprende desde su textura, olor y sabor hasta su actividad acuosa (Aw) y carga microbiana. Con respecto a las primeras, la textura será más dura, su olor variará, el sabor se intensificará, según sus aditivos y presentará un color oscuro. Cabe aclarar que estas características se deben a la reducción de agua donde la carne pierde hasta un $60 \%$ de su peso y al ser secada la carga microbiana no prolifera, lo que dará mayor tiempo de conservación.

\section{Aspectos físicos del jerky}

૫ Decoloración causada por alteraciones del pigmento muscular.

૫ Decoloración causada por la pérdida de hemoglobina.

- Carne más fibrosa a causa de la ausencia de gran cantidad de grasa.

$\square$ Producción de olores y sabores.

u Diversos sabores encontrados en el jerky los cuales varían dependiendo del maridaje. 


\section{Características organolépticas del jerky}

Tabla 1. Características organolépticas del jerky.

\begin{tabular}{|l|l|l|}
\hline MATERIA PRIMA & \multicolumn{1}{|c|}{ Color y textura } & \multicolumn{1}{c|}{ Aroma y sabor } \\
\hline Jerky (Charqui, carne seca). & $\begin{array}{l}\text { Color rosa algo opaco con } \\
\text { textura suave y más fibrosa, } \\
\text { más frágil a causa de la au- } \\
\text { sencia de gran cantidad de } \\
\text { grasa. }\end{array}$ & $\begin{array}{l}\text { Olor característico de la } \\
\text { carne, agradable. } \\
\text { Sabor del jerky varía a los } \\
\text { condimentos y adobos que } \\
\text { se agreguen y en el que se } \\
\text { maride la carne. } \\
\text { Cabe resaltar que la car- } \\
\text { ne equina tiene un sabor } \\
\text { suave y dulce al ser pasada } \\
\text { por aceite (frita). } \\
\text { En el caso de la elabora- } \\
\text { ción del Jerky sin sabor, } \\
\text { conserva su sabor dulce y } \\
\text { su aroma suave }\end{array}$ \\
\end{tabular}

Fuente: Elaboración propia. Universitaria Agustiniana, 2017.

\section{Cabano}

Según el decreto 2162 de 1983, el cabano es un producto procesado, cocido y embutido. Es elaborado con ingredientes y aditivos permitidos por la normatividad y sometido a un proceso de picado grueso, a un embutido en tripas autorizadas de $22 \mathrm{~mm}$ y a tratamientos térmicos para disminuir su humedad. 
Entonces, es un embutido hecho principalmente a partir de la mezcla de carne de res, cerdo y condimentos. Su textura es muy seca y presenta sabores ahumados, generalmente es largo y bastante delgado. Sus métodos de curación le aportan sabores y aromas distintos a los de una salchicha. Es ideal como snack o aperitivo acompañado con queso. El cabano mide $60 \mathrm{~cm}$ de largo, con un diámetro de $1 \mathrm{~cm}$ aproximadamente, se dobla a la mitad, lo que crea un aspecto característico.

Los cabanos vienen de la palabra Kaban, que significa cerdo en polaco. Sin embargo, se ha creado disputa porque Alemania asegura que la receta es autóctona.

Se conocen datos acerca del consumo de cabano por parte de los viajeros y exploradores como alimento principal, ya que no se daña fácilmente como otros productos embutidos y es fácil de transportar. En Latinoamérica se conoce la producción del cabano a partir de la carne de alpacas, animal que ha abastecido la población peruana durante siglos.

\section{Aspectos físicos del cabano}

૫ Alteración del color durante embutido por medio de la sal curante y condimentos.

૫ Alteración del color durante cocción, pasa de ser un color rojo suave a un rojo cereza intenso.

૫ Alteración del color durante el proceso de secado a temperatura ambiente, de color rojo cereza intensa, pasa a ser de color marrón oscuro o café oscuro. Lo anterior depende del tiempo de exposición que tenga el producto al ambiente.

૫ Cambio en el olor y aroma, de suave a un olor fuerte ácido. 


\section{Características organolépticas del cabano}

Tabla 2. Características organolépticas del cabano.

\begin{tabular}{|l|l|l|}
\hline MATERIA PRIMA & \multicolumn{1}{|c|}{ Color y textura } & \multicolumn{1}{|c|}{ Aroma y sabor } \\
\hline Cabano & $\begin{array}{l}\text { Color rojo cereza en cocción. } \\
\text { Color final a temperatura Am- } \\
\text { biente: marrón oscuro / café } \\
\text { oscuro } \\
\text { Textura: Dura, seca. }\end{array}$ & $\begin{array}{l}\text { Aroma fuerte, ácido, sabor } \\
\text { un poco fuerte, ideal para } \\
\text { ser acompañado con be- } \\
\text { bidas alcohólicas, o como } \\
\text { acompañante en ciertas } \\
\text { preparaciones gastronó- } \\
\text { micas. }\end{array}$ \\
\end{tabular}

Fuente: Elaboración propia. Universitaria Agustiniana, 2017

\section{Aspectos importantes en la elaboración del jerky y el cabano}

La pérdida de agua es indispensable para evitar el crecimiento de los microorganismos en el producto. Sin embargo, esto modifica las características organolépticas reales de la carne (textura, sabor y olor). Cuando se somete la carne a un proceso de deshidratación, o secado, su pH se modifica. Generalmente el pH de la carne de caballo es de 5,8 - 6,0 y está determinado principalmente por la cantidad de ácido láctico que contiene, como en la carne de bovino. 


\section{Ubicación del proyecto. Planta de Beneficio "Los Cristales"}

La planta de beneficio Los Cristales, ubicada en el municipio de Mosquera, Cundinamarca, se caracteriza por tener 6 comercializadores mayoristas de equinos que sacrifican sus animales allí (Tabla 3). El precio oscila de 250.000 a 300.000 pesos colombianos por cada animal en pie, dependiendo de las características del animal, como afirma Nivia \& Vanegas (2014).

\section{Tabla 3.Identificación de comercializadores mayoristas de equi- nos que sacrifican sus animales en la Planta de Beneficio "Los Cristales".}

\begin{tabular}{|c|c|}
\hline Número & Código \\
\hline $\mathbf{1}$ & FD \\
\hline 2 & HF \\
\hline 3 & AF \\
\hline 4 & CB \\
\hline 5 & LF \\
\hline 6 & EF \\
\hline
\end{tabular}

Fuente: Nivia \& Vanegas, 2014

Investigaciones realizadas por Ana Milena Vanegas, veterinaria y zootecnista de la planta, afirman que dentro del matadero se maneja la verificación del estado sanitario de cada animal por medio de un registro de vacunación de enfermedades como encefalitis equina venezolana y la influenza equina. Respecto al transporte de los animales, se encontró que el 80\% de los comercializadores no cuentan con un vehículo adecuado para el viaje de, aproximadamente, 16 horas con una carga de al menos 21 caballos, de los cuales en pocas ocasiones pueden morir del 5\% al 10\% de la población total. 
En lo que respecta a la venta y comercialización de la carne, el $67 \%$ de los comercializadores sacrifican entre 21 a 40 animales en la semana, mientras que los otros sacrifican entre 40 a 80 animales por un costo de 32.000 pesos colombianos.

Los principales destinos de la carne son las industrias transformadoras y expendios de carne fresca principalmente en Bogotá. La producción de carne equina, al igual que la de res, se integra por comercializadores, plantas de beneficio, industrias procesadoras de alimentos, distribuidores mayoristas y minoristas de carne, restaurantes y finalmente, consumidores (Nivia \& Vanegas, 2014). La carne es destinada para la industria transformadora de carnes y expendios de carne fresca principalmente en Bogotá a diferencia de la carne bovina, que es comercializada sin procesamiento para el consumo en los hogares y restaurantes.

Algunos comercializadores optan por realizar procesos de refrigeración y maduración para mejorar las características relacionadas con la presentación, la vida útil, y la calidad de la misma. Según los productos obtenidos tras el sacrificio, se encontró que la piel, la cabeza y las vísceras se destinan a la producción de productos no aptos para el consumo humano, especialmente como alimento para otros animales.

Figura 1. Planta de Beneficio Los Cristales.

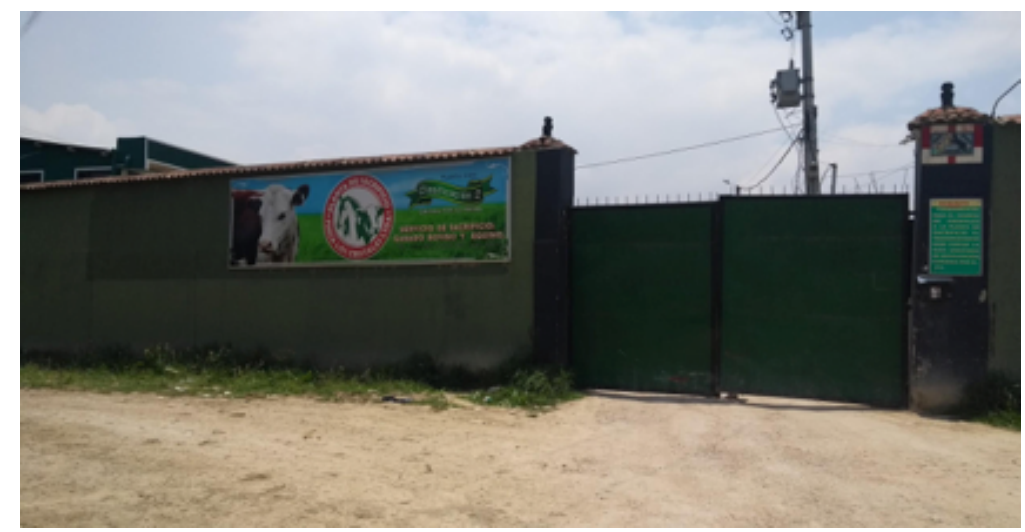

Fuente: Elaboración propia. Universidad Agustiniana 2017 
Los equinos sacrificados en la planta de beneficio son, en su mayoría, comprados directamente de las fincas. Estos son descartados por su edad, por presencia de lesiones y bajo rendimiento. Factores como la edad, peso y sexo del animal son referentes clave para determinar la calidad de sus canales. Los animales proceden, principalmente, de los departamentos de Casanare, Meta, Arauca, Sucre, Caldas y Valle del Cauca y están reportados por el Instituto Agropecuario Colombiano ICA (2012). Estos animales desarrollan actividades como la vaquería y algunas labores de explotación bovina.

\section{Resultados y discusión}

\section{Población y muestra}

El universo se refiere a la Universitaria Agustiniana, de allí sale la población: estudiantes de arquitectura de sexto semestre, estudiantes de Tecnología en gastronomía de quinto semestre y profesores de Tecnología en gastronomía. La muestra fue un total de 60 personas, siendo 20 de cada uno de los programas anteriormente mencionados, a los cuales se les aplicó la encuesta exploratoria.

Para la encuesta descriptiva se seleccionaron 10 personas de cada uno de los aspectos característicos mencionados, la cual se divide en no entrenados, semientrenados y entrenados. Este tipo de muestra se consideró la más apropiada para evaluar conceptos sociales y muestras organolépticas según el tipo de conocimiento que tienen enfocado en la gastronomía. 


\section{Técnicas en de recolección y organización de la información}

La recolección de datos se realizó por medio de cuestionarios con preguntas cerradas para determinar las variables a identificar. Además, se realizaron encuestas y entrevistas para realizar los diagnósticos.

Tabla 4. Ficha técnica encuesta de aceptación.

\begin{tabular}{|l|l|}
\hline \multicolumn{2}{|c|}{ FICHA TÉCNICA DE LA ENCUESTA } \\
\hline Objetivo & $\begin{array}{l}\text { Elaboración de productos Cárnicos a base de carne } \\
\text { de equino. }\end{array}$ \\
\hline Grupo Objetivo & $\begin{array}{l}\text { Profesionales y semiprofesionales en gastronomía. } \\
\text { Particulares de la Universitaria Agustiniana. }\end{array}$ \\
\hline Técnica & Aplicación de un cuestionario base. \\
\hline Cubrimiento & Campus de la Universitaria Agustiniana sede Tagaste. \\
\hline Muestra & Se realizaron 60 encuestas efectivas. \\
\hline Margen de Error & Era una muestra no probabilística. \\
\hline Fecha de aplicación & 13 de Octubre del 2017 \\
\hline
\end{tabular}

Fuente: Elaboración propia. Universitaria Agustiniana, 2017.

\section{Tabulación y análisis de la encuesta exploratoria}

Figura 2. Edades y sexo de la Uniagustiniana.

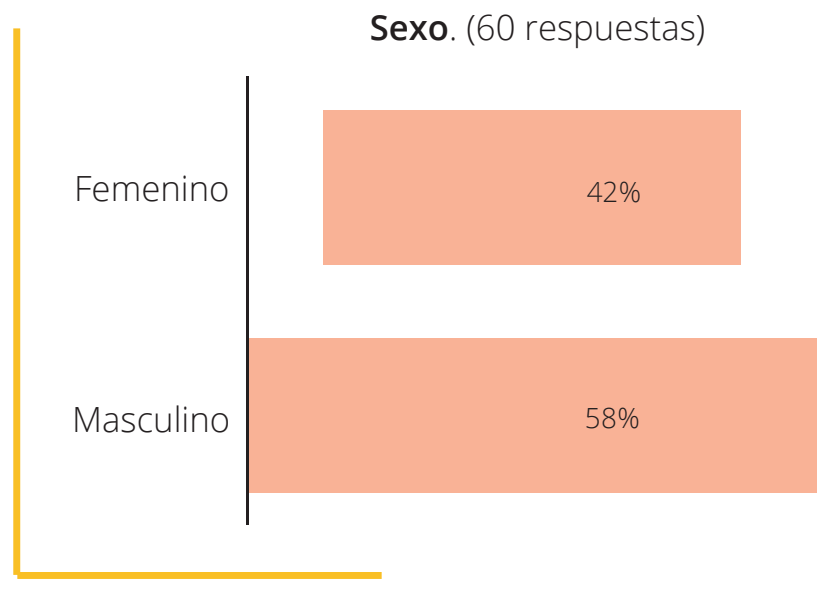


Edad. (60 respuestas)

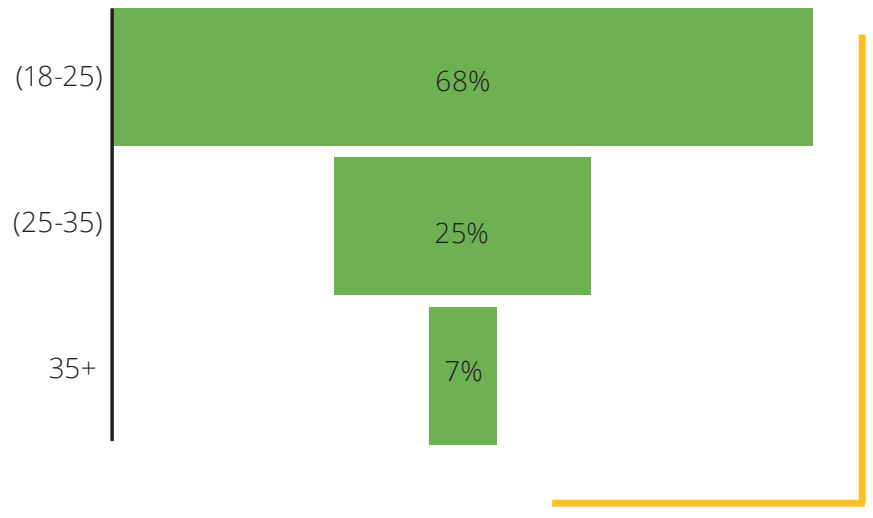

Fuente: Elaboración propia. Universitaria Agustiniana,2017.

Figura 3. Consumo de carne de caballo en Uniagustiniana.

¿Usted ha consumido carne de caballo?. (60 respuestas)

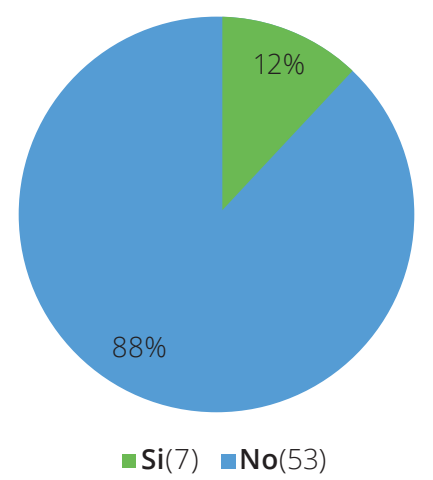

Fuente: Autor. Universitaria Agustiniana, 2017

En esta pregunta se nota una gran preferencia de respuesta siendo no el 88\% (53 respuestas) y sí el 12\% (7 respuestas) restante. Allí se observó el poco consumo de carne equina que las personas de la Universidad Agustiniana manejan, unos por 
mitos sobre el mal manejo de sacrificio y otro por tradiciones que los llevan a consumir carne de res o carne de cerdo más frecuentemente en preparaciones. También porque la sociedad no tiene forma de adquirirla de procedencia buena y legalmente, algunas veces la forma en la que la obtienen es inconscientemente por hacerla pasar por carne de res ya que no diferencian visualmente una de otra.

Figura 4. ¿De qué manera han consumido carne de caballo en la Uniagustiniana?.

\section{Si su respuesta fue si ¿De que manera la ha consumido?. (7 respuestas)}

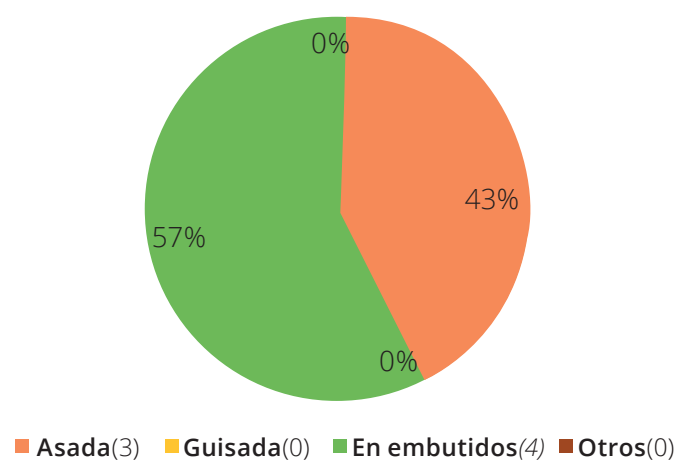

Fuente: Elaboración propia. Universitaria Agustiniana, 2017.

Se observó que el 57\% (4 respuestas) afirma haberlo consumido de productos cárnicos embutidos porque son conscientes que algunas salsamentarias donde consiguen estos productos utilizan carne equina para reducir sus costos y así poder vender mucho más económico el producto obteniendo con sabores similares. El 
43\% (3 respuestas) afirma haberla consumido asada, ya que en el momento de asarla popularmente se conoce que la carne equina es espumosa y tiende a hincharse. Mientras que el guisado no tuvo respuesta alguna (0\% y otros 0\%).

Figura 5. Consumo de productos cárnicos de equino en la Uniagustiniana.

Si su respuesta fue no ¿Consumiría productos elaborados a partir de carne de caballo? (53 respuestas)

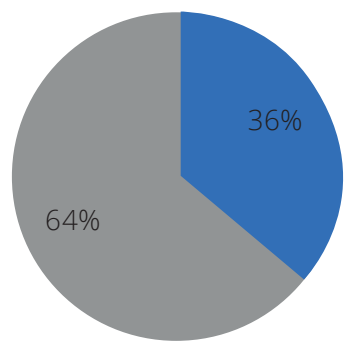

$\varpi \mathrm{Si}(21) \varpi \mathrm{No}(33)$

Fuente: Autor Universitaria Agustiniana.

Figura 6. Conocimiento propiedades nutricionales de la carne de caballo en Uniagustiniana. ¿Sabe usted las propiedades nutricionales que contiene la carne de caballo? (60 respuestas)

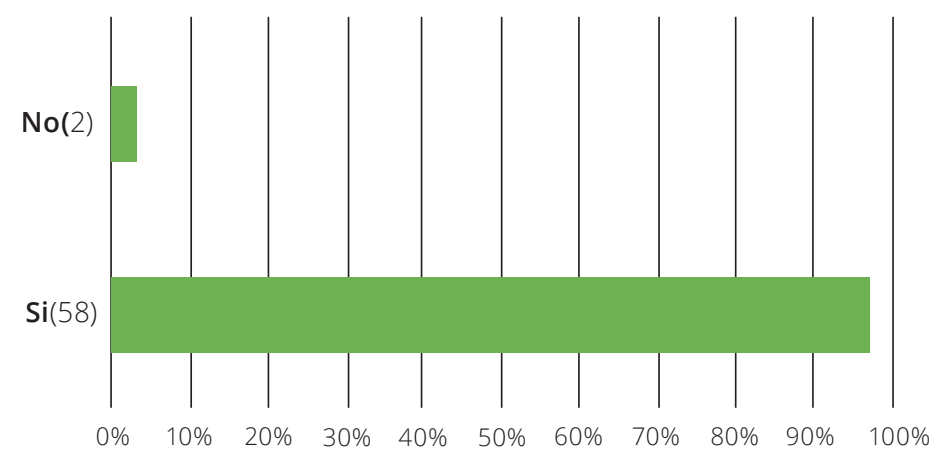

Fuente: Autor. Universitaria Agustiniana 2017 
La respuesta popular fue SI (58 respuestas) gracias al folleto informativo que se entregó junto a la encuesta para tener una introducción sobre el tema. También ayudó a tener previos conocimientos sobre las propiedades nutricionales de la carne equina.

Figura 7. Conocimiento legalidad sacrificio y consumo de carne de caballo en Uniagustiniana.

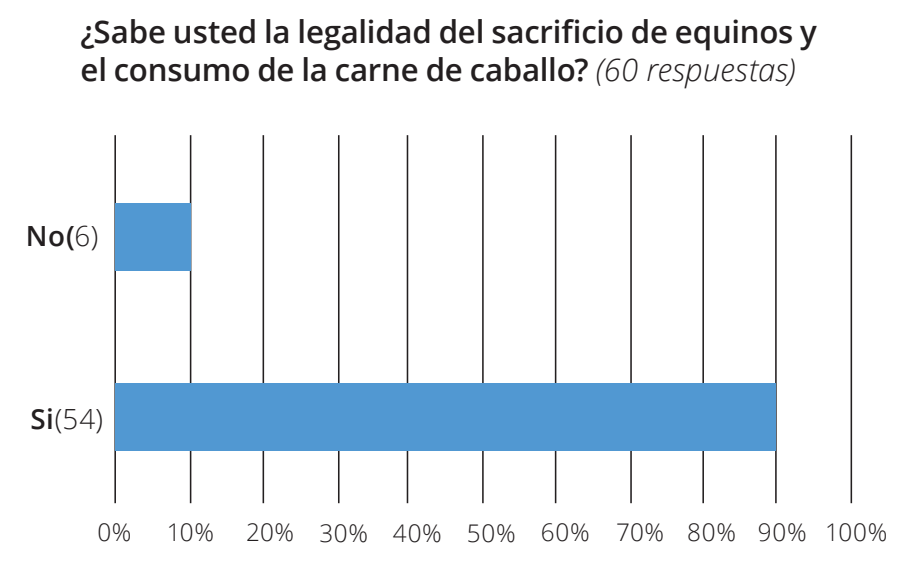

Fuente: Elaboración propia. Universitaria Agustiniana 2017

Según el gráfico, la respuesta del SI 90\% (54 respuestas) predominó gracias al folleto informativo leído previamente por los encuestados, donde se explicó brevemente la certificación que el Instituto Nacional de Vigilancia de Medicamentos y Alimentos (INVIMA) le concede a la planta de beneficio "Los Cristales". 
Figura 8. Consumo de cabano y/o jerky. ¿Ha consumido Cabano y/o Jerky (carne seca)? (60 respuestas)

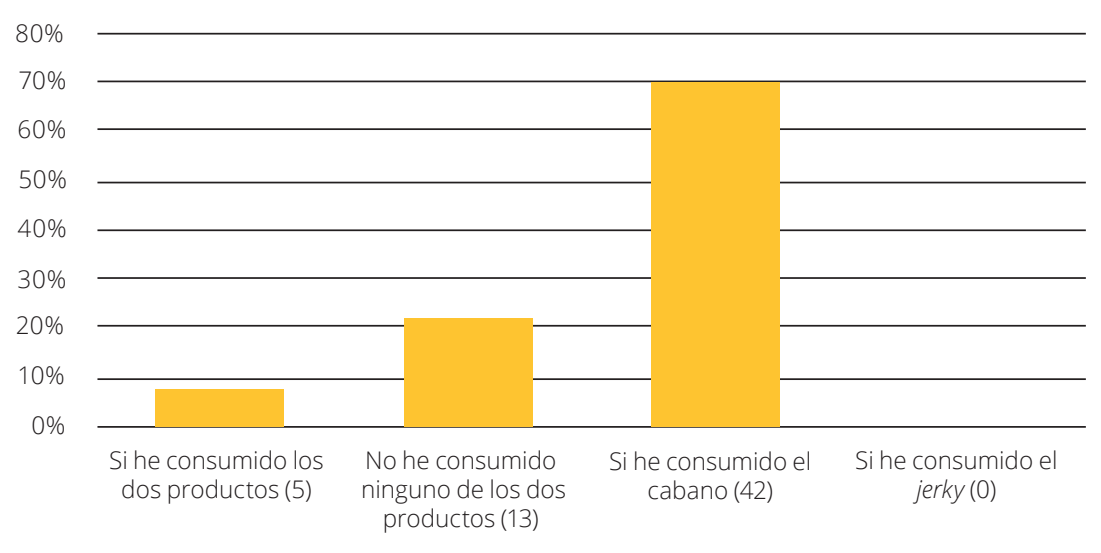

Fuente: Elaboración propia. Universitaria Agustiniana 2017

En los resultados, predominó la opción "Sí he consumido el cabano" con 42 respuestas. Hay que tener presente que por ser un producto de venta común en salsamentarias, y últimamente comercializado en almacenes de cadena, se ha convertido en producto Premium con características de empaque al vacío, buena presentación y de alto consumo en la población. En cambio, la opción "Si he consumido el jerky" obtuvo cero (0) respuestas, posiblemente por ser un producto que no se produce tradicionalmente en el país y no es muy común. Sin embargo, "Sí he consumido los dos productos" tuvo cinco (5) respuestas, esto quiere decir que a pesar del poco conocimiento y consumo, hay personas que sí conocen el jerky, queda preguntarse si se trata de estudiantes de gastronomía. 
Figura 9. Consumo de jerky y cabano con carne equina en la Uniagustiniana.

¿Consumiría alguno de los productos mencionados en la pregunta anterior si estuvieran elaborados a partir de carne de caballo? (60 respuestas)

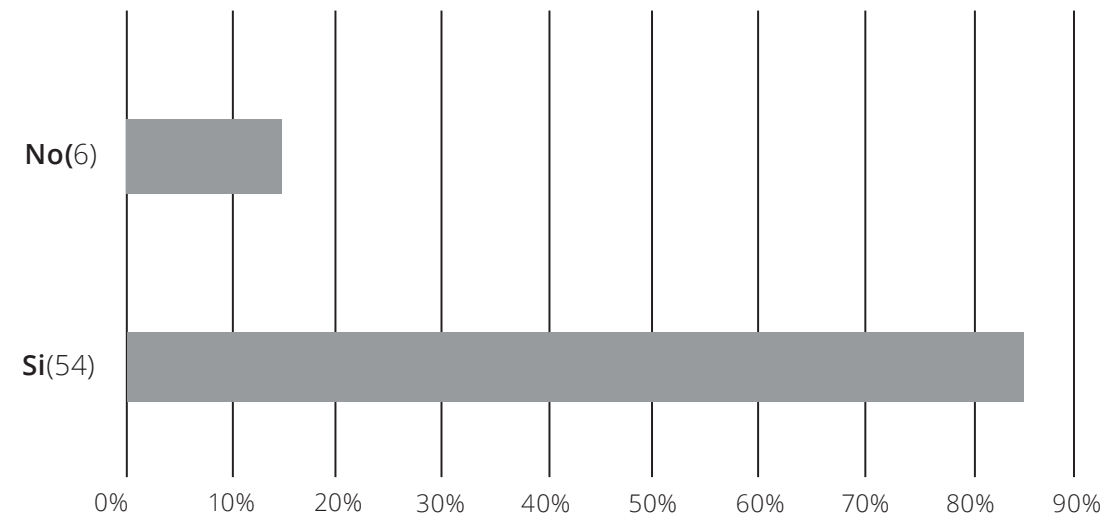

Fuente: Elaboración propia. Universitaria Agustiniana, 2017.

\section{Conclusiones}

Durante la investigación, se dio a conocer el buen manejo de la carne de equino, desde su obtención hasta tu comercialización con respecto a su legalidad vigente en Colombia. También, se estandarizaron correctamente productos cárnicos como el cabano y el jerky por medio de un sustituto cárnico mejorado con carne de equino, los cuales le dieron unas buenas características organolépticas. Además, dichos productos tienen buenas propiedades nutricionales con respecto a la carne de res, en porcentaje de elevada proteína y baja grasa.

Finalmente, se evidenció la aceptación y viabilidad de los productos expuestos a tres tipos de muestras (entrenados, semientrenados y profesionales), los cuales dan vía a la posible introducción de los mismos en la sociedad, de manera paulatina. 


\section{Lista de referencias}

Decreto 2162 de 1983. Producción, procesamiento, transporte y expendio de los productos cárnicos procesados. Recuperado de http://biblioteca.saludcapital.gov.co/img_upload/03d591f205ab80e521292987c313699c/decreto-2162-de-1983.pdf

Instituto Nacional de Vigilancia de Medicamentos y Alimentos INVIMA. (2014). El INVIMA advierte sobre las plantas de beneficio animal de equinos. Recuperado de https://www.invima.gov.co/images/pdf/ informate/COMUNICADO\%20DE\%20ALIMENTOS\%20\%20SACRIF\%C3\%8DCIO\%20ANIMAL\%20DE\%20EQUINOS\%20FINAL\%20OK\%20 16\%20cistina.pdf

Nivia Osuna, A., Belalcázar Zafra, M., \& Vanegas Azuero, A. (2014). Determinación del volumen de sacrificio y evaluación de variables cualitativas y cuantitativas en equinos sacrificados en una planta de beneficio animal. Revista Zootecnia Trop, 32(1): 83-89. Recuperado de http://www.sian.inia.gob.ve/revistas_ci/ZootecniaTropical/zt3201/ pdf/zt3201_nivia.pdf

Norma Técnica Colombiana NTC 4423 Industria Alimentaria. Especias y Condimentos. Instituto Colombiano de Normas Técnicas ICONTEC. Recuperado de https://tienda.icontec.org/wp-content/uploads/ pdfs/NTC4423.pdf

Rodríguez, Fabián (1994). Cría rentable de camélidos sudamericanos. Manual teórico-práctico para su producción y consumo. Recuperado de https://books.google.com.co/books?id=0PXAss8UmOIC 